\title{
THE ACID MUCOPOLYSACCHARIDE AND 5-HYDROXYTRYPTAMINE CONTENT OF HUMAN THROMBOCYTES IN RHEUMATOID ARTHRITIC AND NONARTHRITIC INDIVIDUALS *
}

\author{
By GRACE P. KERBY AND S. M. TAYLOR
}

(From the Department of Medicine, Duke University School of Medicine, Durham, N. C.)

(Submitted for publication January 27, 1959; accepted February 19, 1959)

The occurrence of acid mucopolysaccharides in human thrombocytes has been reported from this laboratory (1). The present continuing study had as its purpose further qualitative characterization and a study of the amounts of the acid mucopolysaccharides present in thrombocytes of patients with rheumatoid arthritis as compared to nonarthritic individuals. Because of the acidic nature of the mucopolysaccharides, it was proposed further to measure the amount of 5-hydroxytryptamine present in the same thrombocyte preparations, to determine if any correlation might exist in the content of these two classes of substances.

The overall results of the qualitative studies suggested the probability that a mixture of acid mucopolysaccharides is present in human thrombocytes. The amount present in thrombocytes per unit of blood was significantly greater in patients with nonrheumatoid inflammatory processes than in the control group, but the amount present per unit of thrombocytes was essentially the same in all categories of patients studied. There was no correlation between amount of acid mucopolysaccharides and amount of 5-hydroxytryptamine in human thrombocytes in the present study.

\section{EXPERIMENTS}

Blood was obtained by venipuncture from hospitalized patients, ${ }^{1}$ using siliconed syringes and dispensing rapidly in approximately $9 \mathrm{ml}$. amounts to siliconed tubes containing $1 \mathrm{ml}$. of 1 per cent disodium ethylenedinitrilo tetraacetate (Eastman) in 0.7 per cent aqueous sodium

* This work was supported by grants from the $\mathrm{Na}$ tional Institute of Arthritis and Metabolic Diseases of the National Institutes of Health, United States Public Health Service; and the American Heart Association.

${ }^{1}$ As in previous investigations (2), three groups of patients were studied. The groups were as previously defined and consisted essentially of Group A with no evidence of inflammatory disease, Group B with significant but nonrheumatoid inflammatory processes and Group $\mathrm{C}$ with unequivocal active rheumatoid arthritis. chloride solution. The blood level in each tube was marked before centrifuging, after which thrombocytes were separated from the blood by the method of Dillard, Brecher and Cronkite (3). The volume of blood used was measured accurately by replacement to mark on the finally emptied tubes, correcting for known volume of anticoagulant; the blood sample usually totaled 50 to 60 $\mathrm{ml}$. from each patient.

The thrombocyte buttons were drained after second centrifuging and the inner walls of each tube were wiped dry with gauze. Saline wash was omitted to avoid trauma to and loss of thrombocytes in a third centrifuging. The thrombocytes were resuspended smoothly ${ }^{2}$ in $25 \mathrm{ml}$. $0.14 \mathrm{M} \mathrm{NaCl}$ in $0.02 \mathrm{M} \mathrm{NaOH}$. Partial disruption of thrombocytes started spontaneously on brief standing at room temperature and was completed by sonication in a Raytheon Sonic Oscillator at $9 \mathrm{KC}$. per second for 10 minutes. Duplicate $9 \mathrm{ml}$. aliquots of the clear sonicate were then carried through perchloric acid precipitation and the subsequent steps for recovery of acid mucopolysaccharides by the method of Bollet, Seraydarian and Simpson (4), the final hexuronic acid content of the fraction being determined by the carbazole color reaction of Dische (5). A $0.5 \mathrm{ml}$. aliquot of the sonicate was used for biuret determination by the method of Jayle, Boussier and Badin (6). ${ }^{3}$ Duplicate $3 \mathrm{ml}$. ali-

2 Preparations uniformly resuspended smoothly. Clumping occurred only with damaged thrombocytes and such preparations were discarded.

3 Biuret determination (expressed as mg. of standard human serum albumin, A.R.C., Squibb) was used as a method for quantitation of thrombocytes in the present study to circumvent the inaccuracies inherent in methods for counting thrombocytes. Since the study was a comparative one, the use of a standard method for recovery of thrombocytes introduced a fairly uniform factor of loss in recovery into all groups. The amount of biuret positive material found in thrombocytes from $100 \mathrm{ml}$. of blood was of an order of magnitude comparable to that observed by the others [summarized by Zucker and Borreli (7) ], on conversion of their data from protein nitrogen per unit of thrombocytes to protein content per usual number of thrombocytes in $100 \mathrm{ml}$. of normal blood. The likelihood of significant contamination of thrombocytes with traces of plasma was discounted since biuret determinations on 1:100 dilutions of plasma supernates revealed no significant differences in plasma biuret level between the three groups studied, in contrast to the sig- 
quots of the sonicate were used for extraction of 5-hydroxytryptamine using the fluorometric method of Udenfriend, Weissbach and Clark (8), with final extraction into $0.1 \mathrm{~N}$ hydrochloric acid and measurement of 5-hydroxytryptamine by use of an Aminco Spectrophotofluorometer with activation at $295 \mathrm{~m} \mu$ and fluorescence at $335 \mathrm{~m} \mu$. Standards of 1,2 and $3 \mu \mathrm{g}$. of serotonin creatinine sulfate (kindly furnished by Abbott Laboratories), were run through the entire extraction procedure with every determination and recovery from thrombocytes was calculated from the standard curve obtained, converting the final values to 5-hydroxytryptamine. ${ }^{4}$

Thrombocytes used for additional biochemical studies were prepared as for the determination of hexuronic acid by the carbazole method. Using thrombocytes prepared from a patient with no evidence of inflammatory disease, hexuronic acid was determined in parallel by the carbazole method and by a modification of the orcinol method of Brown (9). In each of two other similar thrombocyte preparations, parallel determinations were made of the hexuronic acid content by the carbazole method and of the hexosamine content by a modification (10) of the method of Elson and Morgan.

To test the susceptibility of the thrombocyte fraction to hydrolysis by testicular hyaluronidase, thrombocytes from a patient with peptic ulcer were carried through the sonication step noted previously. One aliquot was then incubated for 255 minutes at $37^{\circ}$ with 600 units of Alidase (Schering Corp., commercial testicular hyaluronidase), as were control preparations of a thrombocyte aliquot in buffer and Alidase in buffer. All preparations were then carried through perchloric acid precipitation, dialysis against running water and the subsequent steps of the Bollet procedure for recovery of acid mucopolysaccharides.

For paper chromatography of acid mucopolysaccharides, thrombocytes were carried through perchloric acid precipitation and water dialysis steps, then dried in a Virtis Freeze-Dryer and taken up in small amounts of water. Paper chromatography was carried out by methods previously described $(11,12)$. The authors are indebted to Dr. Karl Meyer for the standard preparations of heparitin sulfate and of chondroitin sulfate A, B and C used for comparison with test samples. Commercial heparin

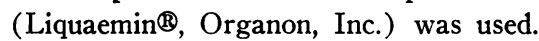

For paper chromatography of hexosamines, thrombocytes were carried through perchloric acid precipitation and water dialysis steps, then brought to $\mathrm{pH} 5.0$ and approximately 0.04 buffer molarity by the addition of $0.1 \mathrm{M}$ phosphate buffer adjusted to $\mathrm{pH} 5.0$ with hydrochloric

nificant differences in thrombocyte biuret level observed between Groups B and C on comparison with Group A (see Results).

4 A full fluorescent spectrum was run on each thrombocyte preparation superimposing this spectrum on that of the serotonin creatinine sulfate standard on an oscilloscopic screen. Identity of spectrum of the thrombocyte preparation with the standard spectrum was always observed. acid. Acid mucopolysaccharides were then precipitated by the addition of cetyl trimethyl ammonium bromide (13) and taken up in a small amount of $4 \mathrm{~N}$ hydrochloric acid. After eight hours of hydrolysis in sealed ampules in flowing steam, the sample was dried by gentle airjet in a jar containing solid sodium hydroxide, taken up in water and adjusted to $\mathrm{pH} 7.5$ to 8.0 by addition of a trace of $0.1 \mathrm{~N}$ sodium hydroxide. Partial purification of hexosamines was then accomplished by passage over a Dowex $50\left(\mathrm{H}^{+}\right.$form $)$column. ${ }^{5}$ The final eluate was dried by airjet as before and taken up in a minute amount of water. The thrombocyte material and the chondroitin sulfate and hexosamine standard preparations were then hydrolyzed in sealed capillary tubes with equal volumes of 2 per cent ninhydrin in water containing 4 per cent pyridine at $100^{\circ} \mathrm{C}$. for 30 minutes (14). The hydrolyzed materials were then chromatographed on Whatman No. 1 paper, descending, in isopropanol-water $(9: 1)^{6}$ and developed by a modification ${ }^{6}$ of the method of Trevelyan, Procter and Harrison (15), substituting 5 per cent aqueous sodium thiosulfate for $6 \mathrm{~N}$ ammonium hydroxide.

\section{RESULTS}

The average values for acid mucopolysaccharides (expressed as hexuronic acid) and 5-hydroxytryptamine recovered from human thrombocytes are recorded in Table I and are compared statistically. The differences noted and their significance are apparent on inspection of the table.

Hexuronic acid levels determined in parallel by the carbazole method and by the orcinol method in acid mucopolysaccharides of human thrombocytes and in various standard acid mucopolysaccharides are recorded in Table II. The carbazole/ orcinol ratio of the thrombocyte preparation approached most closely that expected for chondroitin sulfate A or C (16).

Hexosamine and hexuronic acid levels were determined in parallel in the acid mucopolysaccharides from each of two preparations of human thrombocytes. Expressed as $\mu \mathrm{g}$. per unit of thrombocytes, the comparative levels were 21.1 $\mu \mathrm{g}$. of hexuronic acid and $30.6 \mu \mathrm{g}$. of hexosamine in the first preparation and $12.6 \mu \mathrm{g}$. of hexuronic

5 A commercial chondroitin sulfate (General Biochemicals, Inc.), derived from cartilage and resembling pure chondroitin sulfate $\mathrm{A}$ in its paper chromatographic mobility, was similarly hydrolyzed and purified. A commercial glucosamine hydrochloride (Nutritional Biochemicals Corp.) was purified on a Dowex 50 column. A purified galactosamine preparation was made available through the kindness of Dr. Eugene Davidson.

${ }^{6}$ As suggested by Dr. Eugene Davidson. 
TABLE I

Levels of acid mucopolysaccharides (expressed as hexuronic acid) and 5-hydroxytryptamine in human thrombocytes*

\begin{tabular}{|c|c|c|c|c|c|c|}
\hline \multirow{2}{*}{\multicolumn{2}{|c|}{ Groups }} & \multicolumn{3}{|c|}{ Per thrombocytes from $100 \mathrm{ml}$. of blood } & \multicolumn{2}{|c|}{ Per $100 \mathrm{mg}$. of thrombocyte protein } \\
\hline & & Protein & $\begin{array}{l}\text { Hexuronic } \\
\text { acid }\end{array}$ & $\begin{array}{l}\text { 5-hydroxy- } \\
\text { tryptamine }\end{array}$ & $\begin{array}{l}\text { Hexuronic } \\
\text { acid }\end{array}$ & $\begin{array}{l}\text { 5-hydroxy- } \\
\text { tryptamine }\end{array}$ \\
\hline A) & $\begin{array}{l}\text { Noninflammatory (average } \\
\text { of group } \pm \text { S.D.) }\end{array}$ & $\begin{array}{c}m g . \\
43.8 \pm 12.5\end{array}$ & $\begin{array}{c}\mu g . \\
45.0 \pm 12.9\end{array}$ & $\begin{array}{c}\mu g . \\
16.0 \pm 8.6\end{array}$ & $\begin{array}{c}\mu g . \\
104.7 \pm 23.2\end{array}$ & $\begin{array}{c}\mu g . \\
38.6 \pm 21.9\end{array}$ \\
\hline B) & $\begin{array}{l}\text { Inflammatory } \\
\text { t, p (vs. A) }\end{array}$ & $\begin{array}{c}68.1 \pm 24.3 \\
3.567,<0.01\end{array}$ & $\begin{array}{l}68.6 \pm 25.0 \\
3.207,<0.01\end{array}$ & $\begin{array}{c}12.7 \pm 6.7 \\
1.069,>0.05\end{array}$ & $\begin{array}{c}99.4 \pm 19.7 \\
0.654,>0.05\end{array}$ & $\begin{array}{c}20.0 \pm 11.0 \\
2.543,<0.02\end{array}$ \\
\hline C) & $\begin{array}{l}\text { Rheumatoid } \\
\text { t, p (vs. A) } \\
\text { t, p (vs. B) }\end{array}$ & $\begin{array}{c}63.8 \pm 22.1 \\
3.170,<0.01 \\
0.481,>0.05\end{array}$ & $\begin{array}{c}54.3 \pm 17.1 \\
1.661,>0.05 \\
1.747,>0.05\end{array}$ & $\begin{array}{l}10.1 \pm 5.5 \\
2.147,<0.05 \\
1.052,>0.05\end{array}$ & $\begin{array}{c}90.1 \pm 27.0 \\
1.501,>0.05 \\
1.064,>0.05\end{array}$ & $\begin{array}{c}16.9 \pm 8.0 \\
3.387,<0.01 \\
0.739,>0.05\end{array}$ \\
\hline
\end{tabular}

* Derived from 16 control patients (Group A), 12 nonrheumatoid inflammatory patients (Group B), and 14 rheumatoid patients (Group C).

acid and $27.2 \mu \mathrm{g}$. of hexosamine in the second preparation.

From the thrombocyte fraction incubated with testicular hyaluronidase, $4.49 \mu \mathrm{g}$. (expressed as hexuronic acid) of nondialyzable acid mucopolysaccharides were recovered. An identical aliquot fraction incubated with buffer yielded $12.99 \mu \mathrm{g}$. of hexuronic acid in nondialyzable form and no hexuronic acid could be detected from the hyaluronidase preparation alone.

Paper chromatograms of acid mucopolysaccharides from human thrombocytes are shown in Figure $1 .^{7}$ The thrombocyte material showed a mobility quite different from chondroitin sulfate A and somewhat less than that of heparitin sulfate and chondroitin sulfate $C$. The mobility of the chief component was close to that of chondroitin sulfate $B$ and of the rapid component of heparin. The material did not move as a discrete spot and must be presumed from combined observation of the chromatographic characteristics and the carbazole/orcinol ratio to be a mixture of substances.

Paper chromatograms of hexosamines recovered on hydrolysis of acid mucopolysaccharides from human thrombocytes revealed no trace of glucosamine ${ }^{8}$ but did show a well defined galactosamine spot (Figure 2).

${ }^{7}$ All of the spots photographed were metachromatic as developed with toluidine blue except for a dark blue spot at each origin of the thrombocyte fraction.

8 The method used does not differentiate between glucosamine and mannosamine but does separate both of these substances from galactosamine.

\section{DISCUSSION}

The pattern of quantitative recovery of acid mucopolysaccharides from human thrombocytes differed from that of 5-hydroxytryptamine. The acid mucopolysaccharide content tended to vary with the amount of thrombocyte protein present per unit of blood, whereas the 5-hydroxytryptamine content tended toward constancy per unit of blood regardless of the amount of thrombocyte protein present.

The variation in level of acid mucopolysaccharides from human thrombocytes with the amount of thrombocyte protein present per unit of blood suggested that the acid mucopolysaccharides constituted a structural component of

TABLE II

Carbazole/orcinol ratio in acid mucopolysaccharide fraction from human thrombocytes

\begin{tabular}{cccc}
\hline & \multicolumn{3}{c}{$\begin{array}{c}\text { Hexuronic acid } \\
(\mu \mathrm{g} . \text { per sample) }\end{array}$} \\
\cline { 2 - 4 } Material & Carbazole & Orcinol & Ratio \\
\hline $\begin{array}{c}\text { Acid mucopolysaccharides } \\
\text { of human thrombocytes } \\
\text { from 100 ml. blood }\end{array}$ & 51.7 & 55.9 & 0.925 \\
$\begin{array}{c}\text { Commercial chondroitin } \\
\text { sulfate (see Experiments) } \\
\text { A, }{ }^{*} 100 \mu \mathrm{g} .\end{array}$ & 20.4 & 17.2 & 1.186 \\
$\begin{array}{c}\text { Chondroitin sulfate B, } \dagger \\
100 \mu \mathrm{g} .\end{array}$ & 11.7 & 25.7 & 0.455 \\
$\begin{array}{c}\text { Heparitin sulfate, } \dagger \\
100 \mu \mathrm{g} .\end{array}$ & 29.6 & 16.5 & 1.794 \\
\hline
\end{tabular}

* Run previously by other orcinol methods in parallel with chondroitin sulfate A† to yield carbozole/orcinol ratio identical with that of the standard chondroitin sulfate A. $\dagger$ Obtained through the kindness of Dr. Karl Meyer. 


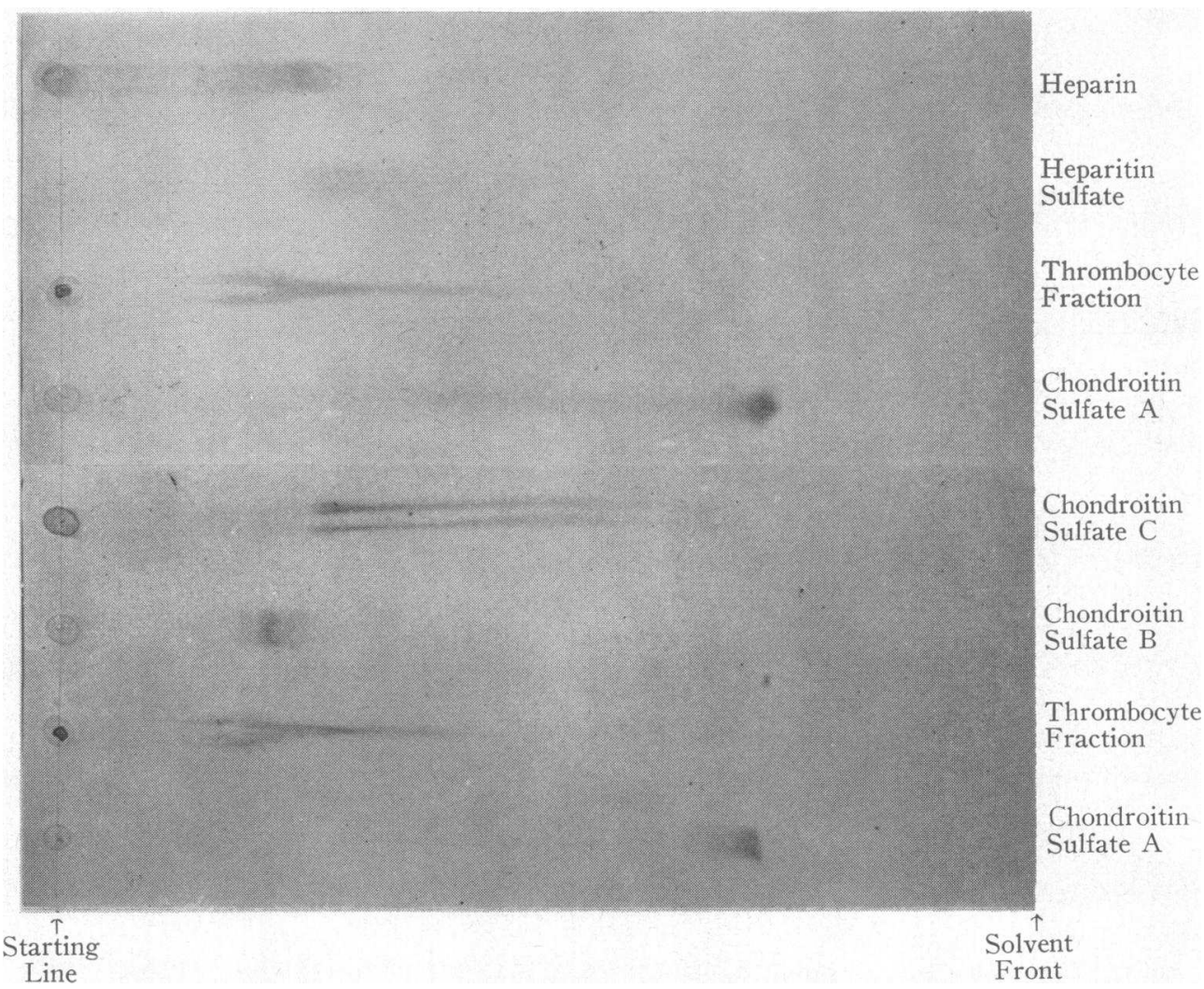

Fig. 1. Chromatographic Comparison of Acid Mucopolysaccharides from Human Thrombocytes with Various Standards

Solvent 48 per cent ethanol in $\mathrm{pH} 6.8,0.067 \mathrm{M}$ phosphate buffer.

thrombocytes or else were present in thrombocytes by virtue of some homeostatically regulated process that kept the amount present relatively constant. As the amount of thrombocyte protein present per unit of blood from patients with nonrheumatoid or rheumatoid inflammatory processes was increased, so also there was noted an increase in the amount of acid mucopolysaccharides

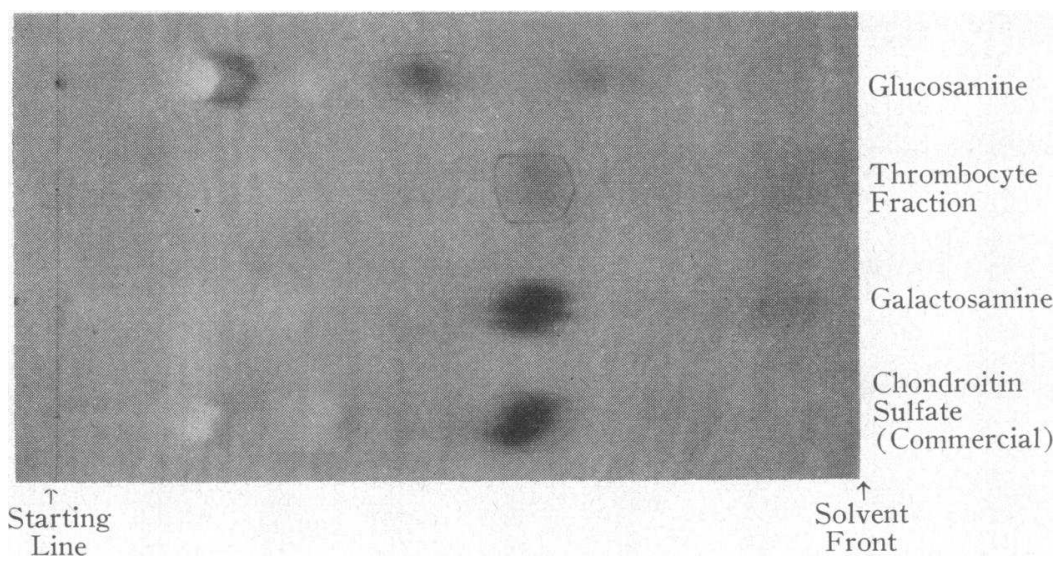

Fig. 2. Chromatographic Comparison of Hexosamines of Hydrolyzed Acid Mucopolysaccharides from Human Thrombocytes with Glucosamine and Galactosamine Standards

Solvent isopropanol-water $(9: 1)$. 
from thrombocytes per unit of blood. The parallel was close in patients with nonrheumatoid inflammatory disease and in patients with no evidence of inflammatory disease. Patients with rheumatoid arthritis, in contrast, showed a somewhat lower ratio of acid mucoplysaccharides to protein in thrombocytes but this lowering of ratio did not achieve statistical significance.

The 5-hydroxytryptamine content on the other hand and as noted showed no positive correlation with the amount of thrombocyte protein present per unit of blood and was in fact slightly less per unit of blood on comparison of the two inflammatory groups $\mathrm{B}$ and $\mathrm{C}$ with the noninflammatory control group $\mathrm{A}$, despite the increased amount of thrombocyte protein present in these two groups. This lesser amount of 5-hydroxytryptamine in thrombocytes per unit of blood was of possible significance statistically $(\mathrm{p}<0.05)$ only on comparison of the rheumatoid group with the control group. The amount of 5-hydroxytryptamine per unit of thrombocyte protein was significantly less in both of the inflammatory groups as compared to the control group. The overall trend of the observations concerning 5-hydroxytryptamine was thus in accord with the concept established earlier by others $(17,18)$ that virtually all of the 5-hydroxytryptamine carried in the blood is bound by thrombocytes and with the conclusion that a fairly uniform total amount is apparently present normally for such binding, since the thrombocyte content of 5-hydroxytryptamine normally remains within fairly uniform limits. The slightly lesser total amount observed in the two inflammatory groups then becomes of interest and one could wonder whether the 5-hydroxytryptamine total content is restored to the blood less quickly than are thrombocytes following the extravascular appearance of 5-hydroxytryptamine which Spector and Willoughby (19) have shown occurs early in the evolution of the inflammatory process.

Qualitative studies of the acid mucopolysaccharides of human thrombocytes yielded conflicting data that is best explained by postulating a mixture of substances. The material yielded nothing resembling chondroitin sulfate $\mathrm{A}$ on paper chromatography and resembled more in its mobility either chondroitin sulfate $B$ or the rapid component of heparin; the mobility was slightly less than that of heparitin sulfate or of chondroitin sulfate $\mathrm{C}$. However it is apparent from inspection of Figure 1 that the overlap in all standards except chondroitin sulfate $A$ was such that other methods had to be utilized for further characterization of the material. The chromatographic data excluded the likelihood of detectable chondroitin sulfate A and showed the fraction to have metachromatic staining qualities and a mobility consistent with any of the other standards used. Of the five acid mucopolysaccharides used as standards, however, only the three chondroitin sulfates contain galactosamine rather than glucosamine or mannosamine $(16,20,21)$. Only galactosamine was detected in the hydrolysate of the acid mucopolysaccharide fraction from human thrombocytes. Thus heparin and heparitin sulfate appeared to be unlikely components of the fraction and interest centered on chondroitin sulfate $\mathrm{B}$ and $\mathrm{C}$. Chondroitin sulfate $\mathrm{B}$ is resistant to testicular hyaluronidase while chondroitin sulfate $C$ is hydrolyzed by this enzyme preparation (22). The thrombocyte fraction was partially hydrolyzed by testicular hyaluronidase. The carbazole/orcinol ratio of pure chondroitin sulfate $B$ is low while that of pure chondroitin sulfate $A$ or $C$ achieves somewhat more than unity (16). The carbazole/orcinol ratio of the thrombocyte material was slightly less than one and definitely in excess of that of pure chondroitin sulfate $B$. It would seem probable that the acid mucopolysaccharides of human thrombocytes are a mixture rather than any new substance. A mixture of chondroitin sulfate $B$ and $C$ would best account for all of the data presented here although there is no conclusive evidence for either substance. The acid mucopolysaccharides from human thrombocytes were quite different in their paper chromatographic mobility from the acid mucopolysaccharides previously recovered from human urine and leukocytes (10).

\section{SUMMARY}

1. Qualitative characterization of the acid mucopolysaccharides of human thrombocytes has yielded data suggesting a mixture of substances. The data suggest but by no means prove the possibility of a mixture of chondroitin sulfates $\mathrm{B}$ and $\mathrm{C}$. 
2. No correlation was found between the acid mucopolysaccharide and the 5-hydroxytryptamine content of human thrombocytes. The acid mucopolysaccharide content correlated with the amount of thrombocyte protein present per unit of blood. The 5-hydroxytryptamine content correlated with the amount of blood from which the thrombocytes were separated.

3. On comparison of three groups of patients (noninflammatory, nonrheumatoid inflammatory and active rheumatoid), the thrombocyte protein level per unit of blood was significantly elevated in the inflammatory and rheumatoid groups, as was the acid mucopolysaccharide content of thrombocytes per unit of blood. The 5-hydroxytryptamine content of thrombocytes, in contrast, was slightly lower in the inflammatory and rheumatoid groups (and to a possibly significant degree in the rheumatoid group), despite the higher level of thrombocyte protein per unit of blood.

\section{REFERENCES}

1. Kerby, G. P., and Langley, N. M. Human thrombocytes and leukocytes as a source of some of the acid mucopolysaccharides of serum. J. Lab. clin. Med. In press.

2. Kerby, G. P. The effect of inflammation on the hexuronate-containing polysaccharides of human plasma. J. clin. Invest. 1958, 37, 962.

3. Dillard, G. H. L., Brecher, G., and Cronkite, E. P. Separation, concentration, and transfusion of platelets. Proc. Soc. exp. Biol. (N. Y.) 1951, 78, 796.

4. Bollet, A. J., Seraydarian, M. W., and Simpson, W. F. Acid mucopolysaccharides in normal serum. J. clin. Invest. 1957, 36, 1328.

5. Dische, Z. A new specific color reaction of hexuronic acids. J. biol. Chem. 1947, 167, 189.

6. Jayle, M. F., Boussier, G., and Badin, J. Microdosage des protéines sériques par la méthode du biuret. Bull. Soc. Chim. biol. (Paris) 1951, 33, 881.

7. Zucker, M. B., and Borrelli, J. A survey of some platelet enzymes and functions: The platelets as the source of normal serum acid glycerophosphatase. Ann. N. Y. Acad. Sci. 1958, 75, 203.

8. Udenfriend, S., Weissbach, H., and Clark, C. T. The estimation of 5-hydroxytryptamine (serotonin) in biological tissues. J. biol. Chem. 1955, 215, 337.

9. Weissmann, B., Meyer, K., Sampson, P., and Linker, A. Isolation of oligosaccharides enzymatically produced from hyaluronic acid. J. biol. Chem. 1954, 208, 417.

10. Kerby, G. P. The occurrence of acid mucopolysaccharides in human leukocytes and urine. J. clin. Invest. 1955, 34, 1738.

11. Kerby, G. P. Chromatographic separation of heparin and chondroitin sulfate. Proc. Soc. exp. Biol. (N. Y.) 1953, 83, 263.

12. Leitner, J. G., and Kerby, G. P. Staining of acid mucopolysaccharides after chromatography on filter paper. Stain Technol. 1954, 29, 257.

13. DiFerrante, N., and Rich, C. The determination of acid aminopolysaccharide in urine. J. Lab. clin. Med. 1956, 48, 491.

14. Stoffyn, P. J., and Jeanloz, R. W. Identification of amino sugars by paper chromatography. Arch. Biochem. 1954, 52, 373.

15. Trevelyan, W. E., Procter, D. P., and Harrison, J. S. Detection of sugars on paper chromatograms. Nature 1950, 166, 444.

16. Hoffman, P., Linker, A., and Meyer, K. Chondroitin sulfates. Fed. Proc. 1958, 17, 1078.

17. Hardisty, R. M., and Stacey, R. S. 5-Hydroxytryptamine in normal human platelets. J. Physiol. 1955, 130, 711.

18. Weissbach, H., Bogdanski, D. F., and Udenfriend, S. Binding of serotonin and other amines by blood platelets. Arch. Biochem. 1958, 73, 492.

19. Spector, W. G., and Willoughby, D. A. 5-Hydroxytryptamine in acute inflammation. Nature 1957, $179,318$.

20. Meyer, K., Grumbach, M. M., Linker, A., and Hoffman, P. Excretion of sulfated mucopolysaccharides in gargoylism (Hurler's syndrome). Proc. Soc. exp. Biol. (N. Y.) 1958, 97, 275.

21. Jeanloz, R. W. Structure of heparin. Fed. Proc. 1958, 17, 1082.

22. Meyer, $K$. The chemistry of the ground substances of connective tissue in Connective Tissue in Health and Disease, G. Asboe-Hansen, Ed., Copenhagen, Ejnar Munksgaard, Publisher, 1954, p. 54.

\section{SPECIAL NOTICE TO SUBSCRIBERS}

Post Offices will no longer forward the Journal when you move.

Please notify The Journal of Clinical Investigation, Business

Office, 333 Cedar Street, New Haven 11, Conn., at once when you have a change of address, and do not omit the zone number if there is one. 